\title{
The Effect of Message Cues on Stigmatization and Support: An Examination of Obesity-Related Conversations on Weibo
}

\section{Yan Su ${ }^{1^{*}}$}

(iD) 0000-0002-1546-2799

\section{Xizhu Xiao ${ }^{1}$}

(iD) 0000-0002-7833-134X

\author{
Wenxuan Shu ${ }^{2}$ \\ (iD) 0000-0003-3755-3277 \\ ${ }^{1}$ Edward R. Murrow College of Communication, Washington State University, Pullman, WA, USA \\ ${ }^{2}$ New Oriental Education \& Technology Group, Beijing, CHINA \\ * Corresponding author: yan.su@wsu.edu
}

Citation: Su, Y., Xiao, X., \& Shu, W. (2020). The Effect of Message Cues on Stigmatization and Support: An Examination of Obesity-Related Conversations on Weibo. Online Journal of Communication and Media Technologies, 10(2), e202004. https://doi.org/10.29333/ojcmt/7831

\section{ARTICLE INFO}

Received: 13 Dec 2019

Accepted: 19 Feb 2020

\begin{abstract}
Obesity is inflicting millions of adults and children in China. Although Social media has shown to provide peer support to obese individuals, it also contributes to stigmatization of obesity. Therefore, monitoring social media conversations about obesity seems critical for health researchers to address this health risk. With a sample of 222 original Weibo posts and 10,640 responses, this content analysis examined the portrayal of Chinese media's online accounts about obesity, as well as its effects on stigmatization and support among the followers. The study revealed that the followers were more likely to stigmatize obesity when the media depicted it as a cosmetic issue, in a teasing context, and targeted at specific individuals. However, definitional focus of social burden and genetic, environmental, and family attributes were found to trigger supports. Implications are discussed.
\end{abstract}

Keywords: obesity, stigma, support, social media, Weibo, definitional focus

\section{INTRODUCTION}

Obesity, a medical condition in which excess body fat has accumulated to the extent that causes negative effects on health, is inflicting 57 million adults and 15 million children in China (Zhuang, 2017). Past research has shown that social media helps obese individuals in various ways including facilitating education, engagement, and peer support (Ashrafian et al., 2014; Chang, Chopra, Zhang \& Woolford, 2013). However, its influences on stigmatization remain overlooked in China. Stigmatization of obesity, defined as the social construction devaluing obese persons has a range of adverse impacts including preventing them from pursuing life-long goals (Puhl \& Heuer, 2010) and increasing health risks of functional disability (Schafer \& Ferraro, 2011).

Moreover, obesity is not only a health issue in China. It is commonly perceived that the prevalence of obesity in China was due to the incompatibility between its rapid economic growth that pulled Chinese people out of food scarcity and the lack of health concepts among its people (Hunt, 2019). Despite the health and social consequences associated with obesity, research that investigated media coverage, particularly social media discussions, of obesity is scant, compared to other issues such as autism, depression, and schizophrenia (e.g., Bie \& Tang, 2015; Wang \& Liu, 2016; Yang \& Parrott, 2017).

Social media has been shown to help reach self-stigmatized population suffering from obesity (e.g., Ashrafian et al., 2014; Chang, Chopra, Zhang \& Woolford, 2013). Weibo, a Twitter-like social media in China,

Copyright (c) $\mathbf{2 0 2 0}$ by authors; licensee OJCMT. This article is an open access article distributed under the terms and conditions of the Creative Commons Attribution License (http://creativecommons.org/licenses/by/4.0/). 
has garnered 446 million active users by 2018 (Smith, 2019). Previous studies indicated that Weibo has a wide range of positive effects on health issues such as reducing stigmatization toward mentally ill individuals (e.g., Wang \& Liu, 2016). As Bomsel (2014) further highlighted, "Weibo is more than a media, a brand, or a corporation. It is a piece of the Chinese institutional transition" (p.120). Weibo has mobilized grass-roots activities, deconstructed the public's stereotypes of many social issues and groups, and successfully forced the authority to address the public concerns and adjust their decision-making (Tu, 2016). Therefore, given its unparalleled influence on health behavior education and social structures, monitoring the conversation of obesity on Weibo is important.

Obesity in China has not received enough attention in the health communication academia, even though the country has the world's biggest population of obese children and second largest of obese adults (Zhuang, 2017). The current study is the first known attempt probing into the social construction of obesity on Chinese social media, Weibo. Using a sample of 222 Weibo posts, this study examines social media's role in reducing the public stigma toward obese individuals. Specifically, we examine whether the presence of different focuses of obesity defining, causal attributions of obesity, story contexts of depictions and levels of storytelling in the obesity-related discourses on Weibo have impacts on the general population regarding stigmatization and support of obesity.

\section{LITERATURE REVIEW}

\section{Health Communication in the Digital Age}

The pervasiveness of new media technology provides various opportunities for citizens to engage in news content creations. Social media, as a rapidly growing communication outlet, not only allows users to selectively consume information of their interests, but also easily disseminate information to their social networks (Weeks \& Holbert, 2013). Considered as a "participative Internet", social media have substantial merits in health promotion and education (Korda \& Itani, 2013). For example, user-generated content on social media provide real-time data for health education professionals to develop customized health messages to their target audience (Korda \& Itani, 2013). However, social media is also considered as an arena where stigmatization can easily flourish (McNeil, Brna \& Gordon, 2012). For instance, through analyzing Twitter data, McNeil et al. (2012) found that near half of tweets about seizures were derogatory and stigmatization about this illness continued to emerge. The ease of information proliferation also perpetuated such stigma (Wang \& Liu, 2016).

That being said, the role social media plays in deconstructing the conventional paradigm of media effects is undeniable (Bennett \& lyengar, 2008). First of all, social media disrupts the traditional two-step flow of communication model (Wang \& Liu, 2016). Zhang, Zhao and Xu (2015) found that on Weibo multiple peaks of discussions about a topic existed. While verified users shaped the discussion on Weibo sphere during the first peak, the grass-roots users (e.g., non-verified users) were found to contribute to other peaks, which usually garnered remarkably more traction than the first (Zhang et al., 2015). Second, social media contributes to "self-mobilization, mobilization of others, and social coordination" (Su, 2019, p. 495). For instance, social media users sometimes act as citizen journalists by providing first-hand sources for state media and thus challenge the role of traditional media as a dominant agenda-setter (Huang \& Sun, 2016; Su, 2019). Therefore, scholars argued that the "one-to-many" and "one-to-one" communication patterns have shifted to the pattern of "many-to-many" among the networked audience (Jensen, 2009, p. 335). With these in mind, understanding the way of a health issue being constructed and discussed on social media is important.

Previous research has indicated the importance of information source in health communication (Lee \& Sundar, 2012). This is particularly true in the context of social media. As stated above, sources and their impacts in social media present a tendency of multiplexity. Empirical studies have suggested that authoritative sources are more influential than other sources in the realm of social media, accelerating the dissemination of information and eliciting more engagement (e.g., Lee \& Sundar, 2012). One of the types of authoritative sources is mainstream media (Wang \& Liu, 2016) and its credibility is often extended to the domain of social media. Plenty of mainstream media have initiated their online accounts, which garnered many users that treat the former as the most credible and frequently used sources for their everyday news. Through a social 
network analysis, Yun and colleagues (2016) found that media or organizational Twitter accounts were relatively more effective in spreading flu-related messages; these authoritative accounts were also more likely to "stay active in a longer period compared to other influential individual accounts" (Yun et al., 2016, p. 67). In other words, the influence of social media accounts of the mainstream media on individuals' health and wellbeing cannot be negligible. Therefore, we aim to investigate the relationship between mainstream media's portrayal of and their followers' corresponding attitude toward a stigmatized health issue.

\section{The Media Construction of Obesity Stigma}

In the past decades, plenty of scholars have reported the hazard of obesity stigmatization. For instance, perceived weight discrimination was found to hinder obese people from seeking treatment and recovery for other health issues and preventing them from pursuing important life-long goals (Carr \& Friedmann, 2005; Puhl \& Heuer, 2010); the perceived discrimination also increased the health risks of functional disability (Schafer \& Ferraro, 2011). However, the stigma of obesity is highly prevalent in our society (Aramburu, Drury \& Louis, 2002) as well as in media portrayal. In the process of media construction of obesity stigma, a few vital elements are acknowledged: definitional focuses, causal attributions, story contexts, and the level that stories been told (e.g., Hilton, Patterson \& Teyhan, 2012).

Definitional focuses. Given that obesity-caused problems were mentioned extensively in media coverage, Hilton et al. (2012) empirically summarized four most commonly reported focuses in defining obesity in media coverage: (a) obesity as a risk to health, (b) obesity as a cosmetic issue, (c) obesity as a burden to the National Health Service (NHS), and (d) obesity as an economic cost to society. These problems were also echoed in other studies. For example, Saguy and Almeling (2008) also found that media coverage was prone to dramatization health risks associated with obesity, such that highlight individual blame for weight, which lead to the formation of an "obesity epidemic." Once a health risk is perceived as "real" through heavy utilization of such framing mechanism, "whether that danger was knowingly or intentionally created by others is often crucial to assigning blame" (Lawrence, 2004, p. 59). Moreover, obesity was often associated with beauty dilemma in media coverage (Sandberg, 2007). Such long-term social construction has contributed to a mainstream aesthetic orientation worldwide that endorses thinness and induces stronger social distance attitudes and more negative attitudes toward people suffering from obesity (Pearl, Pulh, \& Brownell, 2012). This is particularly true in China. Researchers found that cosmetic considerations among Chinese individuals were increasingly in line with thinness (Zhang, 2012); also, there's a strong relationship found between thin characters and positive traits such as sociable, kind, happy, successful, whereas obese characters, on the contrary, were more likely to be portrayed as possessing negative traits such as unattractive (Herbozo, Tantleff-Dunn, Gokee-Larose \& Thompson, 2004). In addition, a great deal of media coverage reported on the economic cost to the NHS and to society as a whole (Hilton et al., 2012). Both these definitional focuses boost stigmatized perceptions of obese people as they are often reported to have high medical, psychological, and social costs, while the treatments are usually ineffective (Sikorski et al., 2011; Withrow \& Alter, 2011; Wooley \& Garner, 1991; Wyatt, Winters \& Dubbert, 2006).

Causal attributions. An attribution is a form of social knowledge or social attitude that shapes individuals' opinions, attitudes, and behaviors (Sun, Krakow, John, Liu \& Weaver, 2016). Causal attributions, in the current study, are inferences or consequences drawn from obesity. Previous empirical research reached a tentative consensus that causal attributions are associated with obesity stigma (e.g., Hilbert et al., 2008). More specifically, beliefs about personal reasons, such as lacking personal control and having an unhealthy diet, are more likely to trigger discrimination toward obese patients (Kim \& Willis, 2007). However, if one's obesity is caused by genetic reasons such as heredity, the person was less discriminated against (Hilbert et al., 2008).

Apart from internal factors including personal behaviors and genetic reasons, obesity can also be externally attributed. Environmental reasons such as the development of the fast food industry and geographic locations (Barness, Opitz \& Gilbert-Barness, 2007) are also frequently discussed when explaining obesity. For instance, a person is less stigmatized when he/she got obesity due to reasons beyond his/her control (Corrigan et al., 2000). However, mixed results also exist. For example, Wang and Liu (2016) found that attributing diseases to external causes such as parental causes have extremely limited effects on either reduction or reinforcement of stigma. Given these antithetical evidences, it will beneficial for scholars to replicate this approach within different cultures. 
Contexts. Contexts, the circumstances that the stories were depicted, were also found to have impacts on the stigmatization of certain health issues (Corrigan et al., 2005). Through content analyzing the obesityrelated YouTube videos, Yoo and Kim (2012) found that weight-based teasing videos usually generated a larger number of responses, which might set some sort of normative perceptions among millions of YouTube users. Wang and Liu (2016) also documented that greater percentage of original posts in the social crime context in the depictions of people with mental illness elicited stigmatization, whereas health contexts triggered more supporting responses among social media users. In other words, the overall context in which a disease is depicted will determine the information included and excluded in its depiction.

Levels of storytelling. Among the human-included portrayals of obesity, the depictions can usually be dichotomized as targeting at obese individuals and at obese groups (Narin \& Coverdale, 2005). Prior researchers reported that illness-related personal stories accounted for an extremely small portion of news coverage (Narin \& Coverdale, 2005). Some scholars probing the relationship between media framing and reader commentary revealed that media consumers are more likely to disclose their personal experiences when the media coverage is framed in a way that challenges stigmatization. (e.g., Gwarjanski \& Parrott, 2018). However, the glaring hole exhibited in the extant literature is that extremely limited studies have investigated whether the levels in which a story is told have an impact on the reactions among its consumers.

Psychological scholars, however, confirmed the existence of the tendency that individuals are more willing to provide greater aid when an identifiable person is observed under hardship than to a large, vaguely defined group with the same need. This tendency was defined as the "identifiable victim effect" (Kogut \& Ritov, 2005). Unfortunately, the application of identifiable victim effects in the realm of health communication was found mostly absent.

Therefore, in light of the reviewed literature, we intend to examine whether these stigma-related problems in the media coverage of obesity were associated with the attitudes of the audience. To this end, we treat the posts generated by the mainstream media's official Weibo accounts as the original tweets and the replies and retweets of the followers as the response tweets. Thus, we propose the following hypotheses and research questions.

H1: All these four definitional focuses of obesity-caused problems in the original tweets will be associated with significantly higher stigmatization than supports in response tweets.

H2a: Personal cause of obesity in the original posts is more likely to be associated with significantly more stigmatization than support in the responses.

H2b: The genetic cause of obesity in the original posts is more likely to be associated with significantly less stigmatization than support in the responses.

H2c: The environmental cause of obesity in the original posts is more likely tobe associated with significantly less stigmatization than support in the response posts.

RQ1: Were the presence of parental cause of obesity in the original posts associated with higher stigmatization than support among the responses?

RQ2: What contexts present in the original posts were associated with higher stigmatization among the responses?

RQ3: What level of storytelling present in the original posts were associated with higher stigmatization among the responses?

\section{METHOD}

\section{Sampling}

To locate the discussion posts on obesity, we initially selected the top 10 mainstream media according to the China Media Mobile Communication Index Report (2014) developed by the Center for Studies of Information Resources at Wuhan University \& People.cn Institute. The ranking was based on the level of information dissemination on mobile communication platforms. Our list of ten outlets prioritizes Weibo accounts based on the number of followers each official account has, which includes: People's Daily, Xinhua Viewpoint, CCTV News, China Daily, Global Times, Southern Metropolis Daily, Southern Weekly, The Beijing 


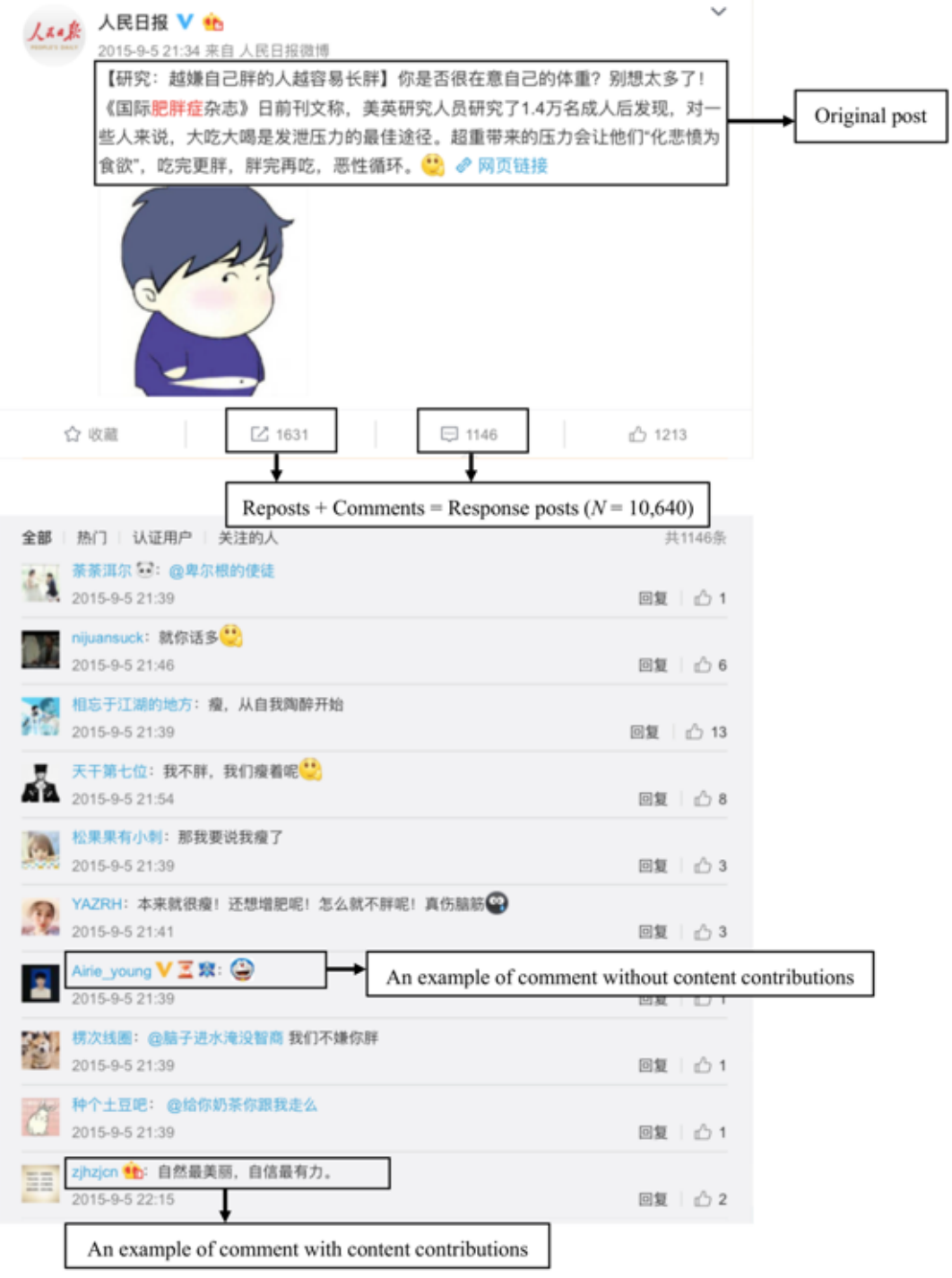

Figure 1. An exemplification of original and response posts

News, Life Week, and Phoenix TV. After the media accounts were identified, the keywords "obese" ("肥胖" in Chinese) and "obesity" (“肥胖症" in Chinese) were adopted to identify original posts pertaining to obesity. All posts including the above keywords generated by the 10 media accounts from August 14, 2009, when Weibo was first launched, to August 14, 2018, were harvested. This 9-year time span allows the exhaustiveness of the relevant data since the birth of Weibo and addresses the puzzle that previous content analysts often failed to gauge shifts and variations over time (Entman, 2010).

Our next concern was about the data noise (Zamith \& Lewis, 2015). All the coders first manually went through all the data and removed the duplicated posts. Next, replicating Su (2019), the coders were verified the extent of noise and manually removed all the advertisements, posts that only contained a single word, hashtag(s), link(s), or visual contents such as picture(s) and video but free from any other text, and tweets not related to the discussion of obesity (Frederick et al., 2015). Finally, 222 posts were yielded.

To investigate how Weibo users responded to the original message cues generated by selected mainstream media accounts, we replicated the approach of previous studies (e.g., Wang \& Liu, 2016) and sampled the engagement from the followers of these accounts, which included both their comments and reposts. These posts were identified as response posts. We harvested the first up to 50 comments and 50 reposts of each original post. Figure 1 exhibits how our original posts look like and how the response posts were identified and harvested. Similarly, we manually excluded the response posts that contained only emoticons, links, or equivalent texts that were not codable, which finally yielded 10,640 posts. 


\section{Coding}

The sample was coded at individual post or individual response level. $25 \%$ of the original $(N=56)$ and $25 \%$ of the response posts $(N=2,660)$ were randomly selected and coded by two independent coders. The Krippendorff's alpha of all variables ranged from 0.80 to 1.00, indicating acceptable levels of intercoder reliability (Krippendorff, 2004). Independent sample $t$-tests and Wilcoxon signed-rank tests were performed to verify the hypotheses and answer the research questions. Four independent variables were coded for original posts, namely, definitional focuses, causal attributions, contexts, and levels of storytelling. Two dependent variables were coded for response posts, namely, stigmatization and support. The presence of each subset of variables was coded $(0=$ absent, $1=$ present $)$.

Definitional focuses. Adopting from Hilton et al.'s (2012) coding scheme, we coded the definitional focuses associated with obesity, including (1) Risk to health, (2) Cosmetic issue, (3) Burden to NHS, and (4) Economic cost. Descriptive analyses showed that definitional focuses on the risk to health occurred with the greatest frequency (37.6.4\%). However, due to the relatively low frequency of the other three definitive focuses, these four definitional focuses were collapsed and dummy coded ( $0=$ absent, $1=$ present).

Causal attributions. Four agents of causal attributions were coded. Original posts indicating that the person had obesity because of heredity were coded as a biological or genetic cause. Original posts identifying changes in natural and societal environment (e.g., development of the fast food industry), accidents, work issues, and changes in the lifecycle as the cause of obesity, or regarding social tolerance, changes in one's working surrounding, and social support as the main solutions, were coded as environmental cause. Original posts suggesting that people suffering from obesity was due to parental mistakes or abuse (e.g., inadequate feeding), or that parents were responsible for improving the life quality of those obese people, were coded as the parental cause. Original posts indicating that the individual was suffering from obesity because of personal reasons such as character flaws (e.g., lack of self-control, intemperate diet), making them accountable for dealing with their own health issue, were coded as a personal cause. These four subcategories were adopted from previous studies with modifications (e.g., Barnes et al., 2007; Corrigan et al., 2000; Hilbert et al., 2008; Wang \& Liu, 2016). The presence of each causal attribution was coded ( $0=$ absent, $1=$ present).

Contexts. Whether the original post discussed the issue of obesity in a political, economic, health \& lifestyle, social hazard, teasing, or other context was coded. These categories were generated based on topics previously generated and utilized to contextualize stories in journalism (Corrigan et al., 2005). For posts that contained more than one context, only its most prominent context was identified and coded $(0=$ absent and $1=$ present).

Levels of storytelling. Based on the above-reviewed literature, in the current study, we conceptualize the levels of storytelling as whether the post is about a personal story of an obese individual or about the obese people as a group. This was operationalized as individual level- and group level-storytelling. For instance, a story entitled "People in northern China are fatter than in southern China, and Beijing is the city with the highest obesity rate" was coded as group-level storytelling, while a story such as "The plaintiff, Karsten Kartoft, was a child-care worker in his hometown Denmark for 15 years and was fired in 2010. During the 15 years of working, his weight never fell below $160 \mathrm{~kg}$. Kartoft believes that he is unemployed because of obesity" was coded as individuallevel storytelling. The levels of storytelling were treated as mutually exclusive, for posts containing both levels simultaneously, we only coded the most prominent level $(0=$ absent and $1=$ present $)$.

Stigmatization. When it comes to the response posts, we coded the presence of stigmatization and support. Posts that made discriminatory statements against obese individuals such as making fun of them were coded as stigmatization (Corrigan et al., 2005). For instance, in a story about an obese people in Denmark claiming that he was fired due to his obesity, a blogger commented, "No matter how pretty the face is, as long as one is fat, one is ugly." This comment was coded as stigmatization in that it treated obesity as equivalent with ugliness, rather than a normal disease. The presence of stigmatization was coded as $0=$ absent and $1=$ present.

Support. Response posts that advocated encouragement, equal treatment, social inclusion, "or conveyed hope and positive emotions" were coded as support (Wang \& Liu, 2015, p. 40). For instance, in a story about an obese man whose weight threatened his life and was sent to a hospital by his parents, a comment that 
Table 1. Relationship between the presentation of definitional focuses in the original posts and opinions in the response posts

\begin{tabular}{ccccccc}
\hline \multirow{2}{*}{ IV: } & \multicolumn{3}{c}{ DV: Opinions $(\boldsymbol{n}=\mathbf{1 0 , 6 4 0})$} & \multicolumn{2}{c}{$\boldsymbol{t}$-tests (supportive-stigmatizing) } \\
\cline { 2 - 8 } Definitional focuses & Supportive & Stigmatizing & No opinion & $\boldsymbol{t}$-ratio & $\boldsymbol{d} \boldsymbol{f}$ & $\boldsymbol{p}$ \\
\hline Risk to health & $37.6 \%$ & $14.9 \%$ & $1.9 \%$ & 11.56 & 118 & $\star \star \star$ \\
\hline Cosmetic issue & $4.3 \%$ & $8.2 \%$ & $0.6 \%$ & -5.68 & 28 & $\star \star \star$ \\
\hline Burden to NHS & $15.6 \%$ & $10.2 \%$ & $1.1 \%$ & 3.88 & 59 & $\star \star \star$ \\
\hline Economic cost & $2.9 \%$ & 1.4 & $0.2 \%$ & 2.4 & 9 & $\star$ \\
\hline
\end{tabular}

Note: ${ }^{*} p<.05, * \star \star p<.001$

Table 2. Relationship between causal attributions in the original posts and opinions in the response posts

\begin{tabular}{ccccccc}
\hline IV: & \multicolumn{3}{c}{ DV: Opinions $(\boldsymbol{n}=\mathbf{1 0 , 6 4 0})$} & \multicolumn{2}{c}{ t-tests (supportive-stigmatizing) } \\
\cline { 2 - 7 } Causal Attributions & Supportive & Stigmatizing & No opinion & $\boldsymbol{t}$ & $\boldsymbol{d} \boldsymbol{~}$ & $\boldsymbol{p}$ \\
\hline Biological/genetic & $7.7 \%$ & $2 \%$ & $0.3 \%$ & 10.15 & 21 & $\star \star \star$ \\
\hline Environmental & $14.5 \%$ & $6.3 \%$ & $0.7 \%$ & 5.81 & 46 & $\star \star \star$ \\
\hline Parental & $7.7 \%$ & $2.1 \%$ & $0.3 \%$ & 6.22 & 21 & $\star \star \star$ \\
\hline Personal & $26 \%$ & $22.5 \%$ & $1.7 \%$ & 1.78 & 110 & .078 \\
\hline
\end{tabular}

Note: $* \star \star *<.001$

read "Many comments here are really malicious, did you read the full text? The article said that he is obese, metabolic disorders, have you seen that? He started exercising and dieting from the age of seven, and you still said that, it was really disgusting, really disgusting." This comment was coded as support, in that it opposed other stigmatizing comments and emphasized the pathological facts and personal efforts of fighting against obesity of the man in the story. The presence of support was also coded as $0=$ absent and $1=$ present.

The codes of stigmatization and support were treated as inter-dependent, that is, we only coded the most prominent opinion contained in each individual post. If the post did not indicate a stand on the issue, we coded as no opinion.

\section{RESULTS}

$\mathrm{H} 1$ assumed the presence of all definitional focuses of obesity will elicit higher stigmatization than supports in responses. As Table 1 illustrates, definitionally focusing on risk to health [supportive: $M=33.64$, $S D=10$; stigmatizing: $M=13.36, S D=9.68 ; t(118)=11.56, p<.001$ ], burden to NHS [supportive: $M=27.6, S D$ = 9.7; stigmatizing: $M=18.03, S D=10.28 ; t(59)=3.88, p<.001$ ], and economic cost [supportive: $M=30.5, S D$ = 9.95; stigmatizing: $M=14.6, S D=11.24 ; t(9)=2.4, p<.05]$ encourages significantly more support and less stigmatization in response posts. Notably, among the above three definitional focuses, "economic costs" has a relatively small number of original posts $(n=10)$, a Wilcoxon signed-rank test was conducted to verify the statistical significance. As a nonparametric test, the Wilcoxon signed-rank is often considered as an alternative option of $t$-test when analyzing a relatively small sample size or when the data is not normally distributed (Bridge \& Sawilowsky, 1999; De Winter, 2013), According to its output, the initial $t$-test result was supported: $Z=-2.09, p=.037$. However, the original posts defining obesity as a cosmetic issue elicited significantly more stigmatization $(M=29.93$. $S D=7.66)$ than support $(M=15.83, S D=6.81)$. Therefore, $\mathrm{H} 1$ is denied.

$\mathrm{H} 2 \mathrm{a}$ through $\mathrm{H} 2 \mathrm{c}$ and $\mathrm{RQ} 1$ addressed the relationships between different causal attributions in the original posts and support and stigmatization in the response posts. As Table 2 illustrates, implying personal causes in original posts made no significant difference between support and stigmatization in the responses [supportive: $M=24.89, S D=10.27$; stigmatizing: $M=21.54, S D=10.31 ; t(110)=1.78, p=.078$ ]. However, the original posts attributing obesity to biological/generic [supportive: $M=37, S D=6.75$; stigmatizing: $M=9.55$, $S D=6.66 ; t(21)=10.15, p<.001$ ], environmental [supportive: $M=32.91, S D=11.15 ;$ stigmatizing: $M=14.15$, $S D=11.28 ; t(46)=5.81, p<.001$ ], and parental reasons [supportive: $M=37.36, S D=10.08$; stigmatizing: $M=$ $10.05, S D=10.63 ; t(21)=6.22, p<.001]$ elicited significantly more support than stigmatization. Therefore, $\mathrm{H} 2 \mathrm{a}$ is rejected, $\mathrm{H} 2 \mathrm{~b}$ and $\mathrm{H} 2 \mathrm{c}$ are supported.

RQ2 asked about the effects of context on support and stigmatization. As Table 3 illustrates, political context in the original posts made no difference between supportive $(M=29.6, S D=13.09)$ and stigmatizing responses $(M=16.2, S D=12.12) ; t(9)=1.75, p=.113$. Given the relatively small data size of these posts $(n=$ 
Table 3. Relationship between the contexts of the original posts and opinions in the response posts

\begin{tabular}{|c|c|c|c|c|c|c|}
\hline \multirow{2}{*}{$\begin{array}{c}\text { IV: } \\
\text { Contexts }\end{array}$} & \multicolumn{3}{|c|}{ DV: Opinions $(n=10,640)$} & \multicolumn{3}{|c|}{$t$-tests (supportive-stigmatizing) } \\
\hline & Supportive & Stigmatizing & No opinion & t-ratio & $d f$ & $p$ \\
\hline Political & $2.8 \%$ & $1.5 \%$ & $0.2 \%$ & 1.75 & 9 & .113 \\
\hline Economic & $4.9 \%$ & $2.5 \%$ & $0.3 \%$ & 2.6 & 16 & * \\
\hline Health \& Lifestyle & $33.7 \%$ & 20.4 & $1.9 \%$ & 6.24 & 122 & 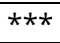 \\
\hline Social Hazard & $11.2 \%$ & $6.7 \%$ & $0.8 \%$ & 4.03 & 38 & $\star \star \star$ \\
\hline Teasing & $1.4 \%$ & $3.2 \%$ & $0.1 \%$ & -6.32 & 9 & 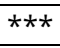 \\
\hline Others & $5.9 \%$ & $1.6 \%$ & $0.1 \%$ & 8.35 & 16 & 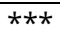 \\
\hline
\end{tabular}

Note: ${ }^{*} p<.05,{ }^{* \star *} p<.001$

Table 4. Wilcoxon's Signed-Rank Test Results of the Relationship between the contexts of the original posts with small sample size and opinions in the response posts

\begin{tabular}{cccccc}
\hline IV: & \multicolumn{3}{c}{ DV: Opinions $(\boldsymbol{n}=\mathbf{1 0 , 6 4 0}$} & \multicolumn{2}{c}{ Wilcoxon's signed-rank test } \\
\cline { 2 - 6 } Contexts & Supportive & Stigmatizing & No opinion & $\boldsymbol{Z}$ & $\boldsymbol{p}$ \\
\hline Political & $2.8 \%$ & $1.5 \%$ & $0.2 \%$ & -1.478, & .139 \\
\hline Economic & $4.9 \%$ & $2.5 \%$ & $0.3 \%$ & 2.226 & $\star$ \\
\hline Teasing & $1.4 \%$ & $3.2 \%$ & $0.1 \%$ & -2.670 & $*$ \\
\hline
\end{tabular}

Note: ${ }^{*} p<.05, * \star \star p<.001$

10). As can be seen in Table 4, Wilcoxon signed-rank test was performed, and the result is buttressed; $Z=-$ $1.478, p=.139$. Moreover, we found that original posts within economic [supportive: $M=30.59, S D=12.33$; stigmatizing: $M=15.53, S D=11.88 ; t(16)=2.6, p<.05 ; Z=-2.226, p<.05$ ], health \& lifestyle [supportive: $M=$ 29.13, $S D=10.32$; stigmatizing: $M=17.63, S D=10.59 ; t(122)=6.24, p<.001$ ], and social hazard [supportive: $M=30.54, S D=12.09$; stigmatizing: $M=15.44, S D=11.9 ; t(38)=24.03, p<.001$ ] contexts were more likely to trigger more supportive than stigmatizing responses. However, the original posts in a teasing context were found to inhibit supportive responses $(M=14.5, S D=5.46)$ and encourage stigmatizing responses $(M=33.7$, $S D=4.6) ; t(9)=-6.32, p<.001$. Given the relatively small number of entertaining original posts $(n=17)$, similarly, a Wilcoxon signed rank test was conducted and the above result is supported; $Z=-2.67, p<.01$ (Table 4).

RQ3 investigated the effects of original posts framed in individual- and group-level on support and stigmatization. According to the results, when the original tweets covered stories in individual-levels, people are more likely to stigmatize $(M=21.35, S D=13.24)$ rather than support $(M=26.35, S D=14.03) ; t(13)=-3.36$, $p<.01$. Given the small number of original posts $(n=14)$, a Wilcoxon signed rank test was conducted and the above result is supported; $Z=-2.419, p=.016$. However, we found that group-level of storytelling made no significant differences between stigmatization $(M=22.00, S D=8.00)$ and support $(M=22.98, S D=7.52)$ in the response posts; $t(43)=1.75, p=.088$. Therefore, $\mathrm{H} 3 \mathrm{a}$ is supported while $\mathrm{H} 3 \mathrm{~b}$ is rejected.

\section{DISCUSSION}

To investigate the extent to which the social media message cues might have contributed to the formation of stigmatization and support of obesity, the present study content analyzes the posts of mainstream media's online accounts and people's responses about obesity on China's extensively used social media, Weibo. More specifically, it examines the effects of definitional focuses, causal attributions, contexts, and levels of storytelling in the original posts on users' viewpoints and exhibited several important findings.

First, this study found that when mainstream media portrayed obesity as a cosmetic issue, their followers were more likely to generate stigmatizing reactions toward obese people. This result confirms the concern that an overemphasis of cosmetic problem caused by obesity will endorse stronger social distance attitudes and negative attitudes toward obese individuals (Pearl et al., 2012), thus gradually lead to the crystallization of stereotypes such as unattractive, unsocial, and unsuccessful of obese people (Herbozo et al., 2004). However, not every type of definitional focus triggered stigmatization. Of the four frequently used definitional focuses (Hilton et al., 2012), those depicting obesity as a risk to health, a burden to NHS, and an economic cost, all led to more supportive reactions. It is understandable that people demonstrate sympathy when they know that obese people suffer from higher risk of health, while the finding that depiction of burden to NHS 
and economy also lead to more support is surprising in that it exhibited different evidence against extant literature (Sikorski et al., 2011), demonstrating another possibility that the more the mainstream media emphasizes social burdens caused by obesity, the more sympathetic the public would be. The different degrees of media saliency may also explain the differing effects of the various definitional focuses. The definitional focus of cosmetic issue might have been more prominent in previous media portrayals and have been more extensively accepted by the society (Pearl et al., 2012; Puhl \& Brownell, 2003; Sandberg, 2007; Zhang, 2012), thus exhibiting a stronger effect than other definitional focuses.

When it comes to the causal attributions of obesity, this study found that attributing obesity to biological/genetic, environmental, and parental causes, all led to more supportive than stigmatizing attitudes among the public. This result confirms the argument in numerous previous studies that when audiences encounter uncontrollable causes of obesity, they are more likely to be tolerant and feel pity for the obese individuals (Corrigan et al., 2000; Hilbert et al., 2008; Smith, 2007; Wang \& Liu, 2016). However, the current study did not find evidence that attributing obesity to personal causes would reduce or reinforce stigmatization among the public, rather, it triggered a similar amount of stigma and support and a relatively smaller number of no-opinion posts. This finding is inconsistent with the extant scholarly assertion that attributing to personal reasons such as lack of personal control and having poor adult role models are more likely to elicit discrimination toward obese patients (Hilbert et al., 2008; Kim \& Willis, 2007), suggesting that personal attribution not necessarily lead to an overwhelming majority of stigmatizing opinions in the public but can contribute to polarized attitudes. In addition, given this study is one of the first attempts probing online discussions about obesity in the Chinese context, we are also highly aware of the possible cultural factors behind this result. Therefore, more research is encouraged to verify the plausibility of this interpretation.

Furthermore, we found that different contexts also led to differing effects on public opinion. Specifically, the utilization of political contexts made no difference in stigmatization and support, while a teasing context elicited more stigmatization. This finding not only confirms the previous studies arguing that weight-based teasing contents prevail on the Internet, but also provides an important extension of them by verifying their speculation that the presence of such teasing contexts can function as setting normative value among Internet users and elicit stigmatization (Yoo \& Kim, 2012). However, we also found that the presence of the other three contexts triggered more supportive responses, which is consistent with the conclusion drawn by previous studies in the same vein (e.g., Wang \& Liu, 2016).

Finally, we found that telling an obese individual's story is more likely to trigger stigmatization among the public while discussing the obese people as a group made no difference between stigmatization and support. This finding is opposite to the "identifiable victim effects" proposal. In the extant body of literature in health communication, given the surprising absent of the investigation of effects of levels of storytelling on audience's attitudes, our finding is very important as it established a new variable for future researchers to adopt and further develop, and generated brand-new evidence.

\section{LIMITATIONS AND IMPLICATIONS}

This study is not without limitations. First, we conducted a quantitative content analysis, which is helpful in perceiving the overall data and drawing cause-and-effect conclusions. However, this approach is not helpful in describing detailed communication messages and texts thus intuitively understand how specific variables were applied in the posts. Therefore, future studies might perform mixed methods to address this concern. Second, due to the constant update and removal of online contents, it was difficult to harvest a systematic sample, especially for the response posts. Although harvesting only a part of valid response posts is extensively utilized by previous research in analyzing online contents, it may cause a certain degree of bias. Third, according to the mechanism of Weibo, every individual user is able to view the comments made by other users. Therefore, it is possible that the effects were not only stemmed from the original posts but also derived from the comments of other commenters and the spiral of silence in the process. Future studies may benefit from developing more sophisticated models to probe these mutual effects among followers. 


\section{REFERENCES}

Aramburu, C., Drury, A., \& Louis, M. (2002). Exploring the Association Between Body Weight, Stigma of Obesity, and Health Care Avoidance. Journal of the American Association of Nurse Practitioners, 14(12). https://doi.org/10.1111/j.1745-7599.2002.tb00089.x

Ashrafian, H., Toma, T., Harling, L., Kerr, K., Athanasiou, T., \& Darzi, A. (2014). Social networking strategies that aim to reduce obesity have achieved significant although modest results. Health Affairs, 33(9), 1641-1647. https://doi.org/10.1377/hlthaff.2014.0370

Barness, L. A., Opitz, J. M., \& Gilbert-Barness, E. (2007). Obesity: Genetic, molecular, and environmental aspects. In American Journal of Medical Genetics, Part A. https://doi.org/10.1002/ajmg.a.32035

Bennett, W. L., \& lyengar, S. (2008). A new era of minimal effects? The changing foundations of political communication. Journal of Communication, 58(4), 707-731. https://doi.org/10.1111/j.14602466.2008.00410.x

Bie, B., \& Tang, L. (2015). Representation of Autism in Leading Newspapers in China: A Content Analysis. Health Communication, 30(9), 884-893. https://doi.org/10.1080/10410236.2014.889063

Bomsel, O. (2014). Is China a Weibo democracy? International Relations and Diplomacy, 2(September 2013), 117.

Carr, D., \& Friedman, M. A. (2005). Is obesity stigmatizing? Body weight, perceived discrimination, and psychological well-being in the United States. Journal of Health and Social Behavior, 46(3), 244-259. https://doi.org/10.1177/002214650504600303

Chang, T., Chopra, V., Zhang, C., \& Woolford, S. J. (2013). The role of social media in online weight management: systematic review. Journal of Medical Internet Research, 15(11). https://doi.org/10.2196/jmir.2852

China Media Mobile Communication Index Report. (2014). People.cn Institute \& Center for Studies of Information Resources at Wuhan University. Retrieved from http://media.people.com.cn/NMediaFile/2014/0630/ MAIN201406301529000210947122844.pdf

Corrigan, P. W., River, L. P., Lundin, R. K., Wasowski, K. U., Campion, J., Mathisen, J., ... Kubiak, M. A. (2000). Stigmatizing attributions about mental illness. Journal of Community Psychology, 28(1), 91-102. https://doi.org/10.1002/(SICI)1520-6629(200001)28:1<91::AID-JCOP9>3.0.CO;2-M

Gwarjanski, A. R., \& Parrott, S. (2018). Schizophrenia in the News: The Role of News Frames in Shaping Online Reader Dialogue about Mental Illness. Health Communication, 33(8), 954-961. https://doi.org/10.1080/10410236.2017.1323320

Herbozo, S., Tantleff-Dunn, S., Gokee-Larose, J., \& Thompson, J. K. (2004). Beauty and thinness messages in children's media: A content analysis. Eating Disorders, 12(1), 21-34. https://doi.org/10.1080/ 10640260490267742

Hilbert, A., Rief, W., \& Braehler, E. (2008). Stigmatizing attitudes toward obesity in a representative populationbased sample. Obesity, 16(7), 1529-1534. https://doi.org/10.1038/oby.2008.263

Huang, R., \& Sun, X. (2016). Dynamic preference revelation and expression of personal frames: how Weibo is used in an anti-nuclear protest in China. Chinese Journal of Communication, 9(4), 385-402. https://doi.org/10.1080/17544750.2016.1206030

Hunt, K. (2019). One in five Chinese children is overweight or obese, study reveals. Retrieved from https://www.cnn.com/2019/03/19/health/china-obesity-kids-int//index.html?no-st=1553828850

Jensen, K. B. (2009). Three-step flow. Journalism, 10(3), 335-337. https://doi.org/10.1177/1464884909102594

Kim, S. H., \& Telleen, M. W. (2017). Talking about School Bullying: News Framing of Who Is Responsible for Causing and Fixing the Problem. Journalism and Mass Communication Quarterly, 94(3), 725-746. https://doi.org/10.1177/1077699016655756

Kim, S., \& Willis, A. L. (2007) Talking about Obesity: News Framing of Who Is Responsible for Causing and Fixing the Problem, Journal of Health Communication, 12:4, 359-376 https://doi.org/10.1080/ 10810730701326051

Kogut, T., \& Ritov, I. (2005). The "identified victim" effect: An identified group, or just a single individual? Journal of Behavioral Decision Making, 18(3), 157-167. https://doi.org/10.1002/bdm.492

Korda, H., \& Itani, Z. (2013). Harnessing Social Media for Health Promotion and Behavior Change. Health Promotion Practice, 14(1), 15-23. https://doi.org/10.1177/1524839911405850 
Krippendorff, K. (2004). Reliability in content analysis: Some common misconceptions and recommendations. Human Communication Research, 30(3), 411-433. https://doi.org/10.1111/j.1468-2958.2004.tb00738.x

Lawrence, R. G. (2004). Framing obesity: The evolution of news discourse on a public health issue. Harvard International Journal of Press/Politics, 9(3), 56-75. https://doi.org/10.1177/1081180X04266581

Lee, J. Y., \& Sundar, S. S. (2013). To Tweet or to Retweet? That Is the Question for Health Professionals on Twitter. Health Communication, 28(5), 509-524. https://doi.org/10.1080/10410236.2012.700391

McNeil, K., Brna, P. M., \& Gordon, K. E. (2012). Epilepsy in the Twitter era: A need to re-tweet the way we think about seizures. Epilepsy and Behavior, 23(2), 127-130. https://doi.org/10.1016/j.yebeh.2011.10.020

Nairn, R. G., \& Coverdale, J. H. (2005). People never see us living well: An appraisal of the personal stories about mental illness in a prospective print media sample. Australian and New Zealand Journal of Psychiatry, 39(4), 281-287. https://doi.org/10.1080/j.1440-1614.2005.01566.x

Pearl, R. L., Puhl, R. M., \& Brownell, K. D. (2012). Positive media portrayals of obese persons: Impact on attitudes and image preferences. Health Psychology, 31(6), 821. https://doi.org/10.1037/a0027189

Puhl, R. M., \& Heuer, C. A. (2010). Obesity stigma: Important considerations for public health. American Journal of Public Health, 100(6), 1019-1028. https://doi.org/10.2105/AJPH.2009.159491

Saguy, A. C., \& Almeling, R. (2008, March). Fat in the Fire? Science, the News Media, and the "Obesity Epidemic" 2. In Sociological Forum (Vol. 23, No. 1, pp. 53-83). Oxford, UK: Blackwell Publishing Ltd. https://doi.org/10.1111/j.1600-0838.2004.00399.x-i1

Sandberg, H. (2007). A matter of looks: The framing of obesity in four Swedish daily newspapers. Communications. https://doi.org/10.1515/COMMUN.2007.018

Schafer, M. H., \& Ferraro, K. F. (2011). The stigma of obesity: Does perceived weight discrimination affect identity and physical health? Social Psychology Quarterly, 74(1), 76-97. https://doi.org/10.1177/0190272511398197

Sikorski, C., Luppa, M., Kaiser, M., Glaesmer, H., Schomerus, G., König, H. H., \& Riedel-Heller, S. G. (2011). The stigma of obesity in the general public and its implications for public health - A systematic review. BMC Public Health, 11(1), 661. https://doi.org/10.1186/1471-2458-11-661

Smith, C. (2019). 70 Amazing Weibo Statistics. Retrieved from https://expandedramblings.com/index.php/ weibo-user-statistics/

Smith, R. (2007). Media Depictions of Health Topics: Challenge and Stigma Formats. Journal of Health Communication, 12(3), 233-249. https://doi.org/10.1080/10810730701266273

$\mathrm{Su}, \mathrm{Y}$. (2019). Exploring the effect of Weibo opinion leaders on the dynamics of public opinion in China: A revisit of the two-step flow of communication. Global Media and China, 4(4), 493-513. https://doi.org/10.1177/2059436419866012

Sun, Y., Krakow, M., John, K. K., Liu, M., \& Weaver, J. (2016). Framing obesity: How news frames shape attributions and behavioral responses. Journal of Health Communication, 21(2), 139-147. https://doi.org/10.1080/10810730.2015.1039676

Tu, F. (2016). WeChat and civil society in China. Communication and the Public, 1(3), 343-350. https://doi.org/10.1177/2057047316667518

Wang, W., \& Liu, Y. (2015). Communication message cues and opinions about people with depression: an investigation of discussion on Weibo. Asian Journal of Communication, 25(1), 33-47. https://doi.org/10.1080/01292986.2014.989238

Wang, W., \& Liu, Y. (2016). Discussing mental illness in Chinese social media: the impact of influential sources on stigmatization and support among their followers. Health Communication, 31(3), 355-363. https://doi.org/10.1080/10410236.2014.957376

Weeks, B. E., \& Holbert, R. L. (2013). Predicting Dissemination of News Content in Social Media: A Focus on Reception, Friending, and Partisanship. Journalism \& Mass Communication Quarterly, 90(2), 212-232. https://doi.org/10.1177/1077699013482906

Withrow, D., \& Alter, D. A. (2011). The economic burden of obesity worldwide: A systematic review of the direct costs of obesity. Obesity Reviews, 12(2), 131-141. https://doi.org/10.1111/j.1467-789X.2009.00712.x

Wooley, S., \& Garner, D. (1991). Obesity treatment: the high cost of false hope. Journal of the American Dietetic Association, 91(10), 1248-1251. 
Wyatt, S. B., Winters, K. P., \& Dubbert, P. M. (2006). Overweight and obesity: Prevalence, consequences, and causes of a growing public health problem. American Journal of the Medical Sciences, 331(4), 166-174. https://doi.org/10.1097/00000441-200604000-00002

Yang, Y., \& Parrott, S. (2018). Schizophrenia in Chinese and U.S. Online News Media: Exploring Cultural Influence on the Mediated Portrayal of Schizophrenia. Health Communication, 33(5), 553-561. https://doi.org/10.1080/10410236.2017.1283562

Yoo, J. H., \& Kim, J. (2012). Obesity in the New Media: A Content Analysis of Obesity Videos on YouTube. Health Communication, 27(1), 86-97. https://doi.org/10.1080/10410236.2011.569003

Yun, G. W., David, M., Park, S., Joa, C. Y., Labbe, B., Lim, J., ... Hyun, D. (2016). Social media and flu: Media Twitter accounts as agenda setters. International Journal of Medical Informatics, 91, 67-73. https://doi.org/10.1016/j.ijmedinf.2016.04.009

Zhang, L., Zhao, J., \& Xu, K. (2016). Who creates Trends in Online Social Media: The Crowd or Opinion Leaders? Journal of Computer-Mediated Communication, 21(1), 1-16. https://doi.org/10.1111/jcc4.12145

Zhuang, P. (2017, June 13). China has largest number of obese children in world, study says. South China Morning Post. Retrieved ON October 11, 2018, from https://www.scmp.com/news/china/society/ article/2098042/china-has-largest-number-obese-children-world-says-study

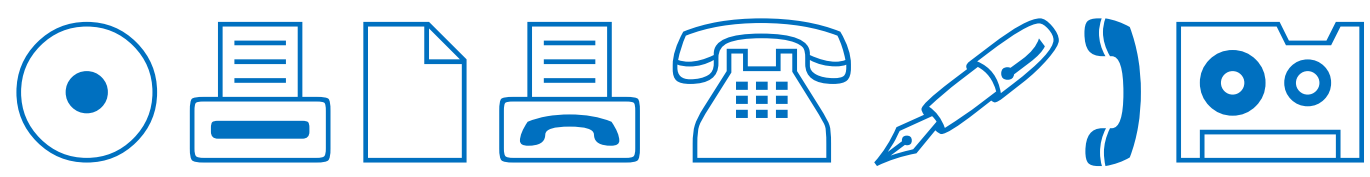

